\title{
The Operating Expense Puzzle of U.S. Green Office Buildings
}

Nikodem Szumilo (University of Cambridge) \& Franz Fuerst (University of Cambridge)

The authors are indebted to the CoStar Group for generously providing the dataset required for this research. 


\section{Abstract}

Cost savings from efficiency gains are at the core of the green building business case. Significantly lower energy bills are said to be a major factor in the green rent premium that has been observed in earlier studies. Our study tests this relationship by inferring energy costs from operating expenses for a large dataset of U.S. office buildings and relating them to the rental rates in a hedonic framework. We find that eco-certification is associated with a higher than anticipated total energy expenditure which is the opposite of its expected effect. While our dataset does not contain a direct measure of actual energy consumption, this result puts the cost-saving argument into question. By contrast, this study confirms earlier findings of a green rent premium but it appears that this premium might be an effect of factors unrelated to a tenant's operating expenses. 


\section{Introduction}

Energy efficiency is thought to bring a plethora of benefits that may affect buildings in different ways and have different financial implications for different market participants. However, core effects of energy efficiency are claimed to steam from a reduced amount of energy used. The associated cost benefit has been claimed to be a key financial driver in making buildings efficient (Oikonomou et al., 2009). Office properties as the most liquid property markets should be quickest to take advantage of this fact. However, many office buildings in US are rented and their lease terms determine who would receive such benefits. In effect, finding out how those are transmitted to rents may be a key to unlocking the benefits of energy efficiency in real estate to governments, corporations and wider society.

This paper focuses on investigating how rents in US office buildings are affected by changes in costs of energy to those buildings. A sample of 2,760 buildings in four biggest US office markets is used to relate rents and operating costs (including enegy costs) to a set of hedonic characteristics of those properties based on existing literature. Energy efficiency is approximated by certification by one of two leading protocols (LEED and EnergStar) and a distinction is made between properties in which a tenant pays for energy and ones where this responsibility remains with the landlord. Changes in energy costs are found to be affecting rents as expected although certified properties seem to pay more for energy. A total premium for eco-certification is consistent with similar reports and a premium for benefits of certification other than related to energy costs is found to have an average value of $4.41 \%$.

\section{Background}

Energy efficiency in office buildings is credited with an ability to offer many benefits to both tenants and owners. The most widely accepted, and perhaps the most intuitive of its effects is the cost saving opportunity arising from the possibility of lower energy bills. In fact, it has been argued that this benefit alone should be enough to generate a positive net present value 
of an energy efficiency investment thus creating a general incentive to undertake such projects (Koomey et al., 2001). the theory that assumes that the benefits of energy efficiency are greater than costs is generally accepted (Harvey, 2006), although questioned by some (ConSol, 2008).

\subsection{Engineering fundamentals}

Assuming that energy efficiency is defined as using less energy to generate the same level of service Most researchers agree that energy efficiency leads to a reduction in energy use given constant demand for energy based services. The fundamentals of such claim stem from engineering calculations of possible energy savings which indicate that various energy systems can achieve a possible reduction of as much as between $40 \%$ (Liu and Claridge, 1999) and 70\% (Withers and Cummings, 1998 and CADDET, 1997). In new constructions the possible overall reduction in energy use falls within a range of $50 \%$ to $75 \%$ (Harvey, 2009) while the total reduction in the existing stock is possible at around $30 \%$ (Kats, 2003).

\subsection{Additional benefits}

A number of additional intangible and difficult-to-measure effects have been found to be associated with energy efficiency. DeCanio and Watkins (1998) find evidence that some firms prefer energy certified buildings due to their effect on branding. They conclude that occupying energy efficient offices is often a part of a comprehensive Corporate Social Responsibility policy. In fact, Eichholtz and co-workers (2010) suggest that this benefit may be so valuable to firms that it may be reflected in higher rents. In the same paper the authors mention that energy efficiency may also affect employee productivity. General economic benefits associated with energy efficiency are expected to have an influence on the demand for such office space. Some evidence of such effect has been found by Fuerst and McAllister (2011b) who found that energy efficient buildings have lower vacancy rates. A higher sales value of such buildings has also been documented (Eichholtz et al., 2010). 


\subsection{The benefit transmission mechanism}

A distinction is often made between energy used to operate a building (site energy) which is reflected in operating expenses and total energy use generated by a building including transmission, production losses and delivery (source energy) (Eichholtz et al., 2010). This paper focuses on energy cost changes thus site energy will be of main concern. Higher energy efficiency should result in a lower use of energy given a constant demand for energy based services. Such cost saving is a real financial benefit that should be possible to capture by market participants. However, given the specific nature of multiple agency relations in the real estate market the transfer of this benefit is not straightforward.

Should a tenant be responsible for an energy bill they should be willing to pay a higher rent to occupy energy efficient space as their total cost of occupancy would remain constant while other benefits (like increased employee productivity or lower volatility of bills) may be available (Fuerst and McAllister, 2011b). Consequently, should the obligation to cover the energy expense remain with the landlord the rent should be reduced by the amount saved on that cost keeping the total cash flow to the owner at the same level. 


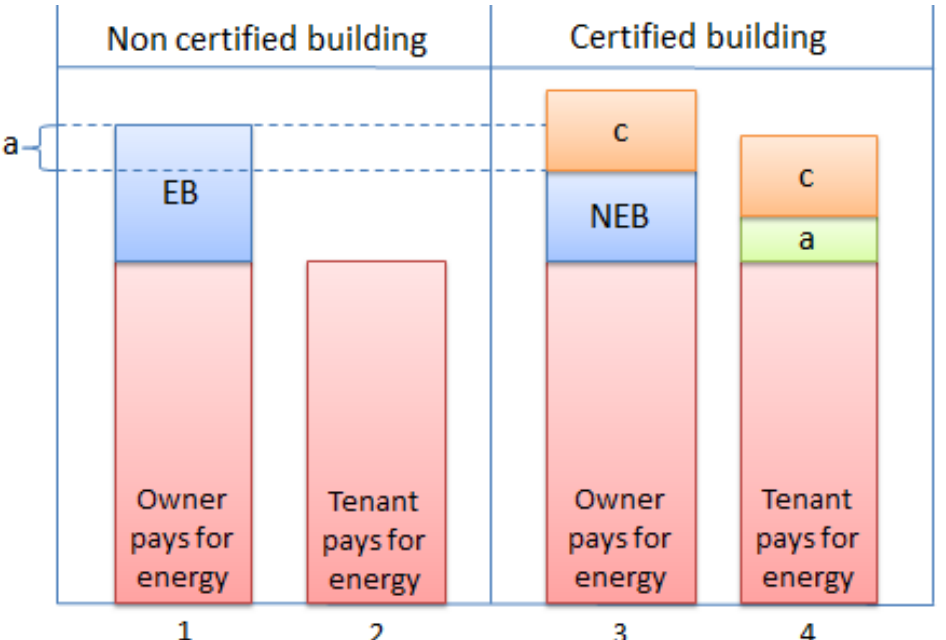

Figure1. Rent paid to owner and lease terms. Columns represent total rent paid.
Assuming that energy efficiency can provide reduction in energy bills (which constitute around $30 \%$ of total operating costs (Eichholtz et al., 2010)) this expense should decrease lowering the total cost of occupying a building. This is illustrated in Figure1 which shows the cash flow from tenant to owner (rent) depending on lease contract terms. Column 1 shows the baseline rent in a case where the owner covers the energy bill which is represented by $E B$. Should this obligation remain with the tenant the rent paid would be smaller by that amount while the total cost to tenant would remain the same. Should the building in question be energy efficient the electricity bill would reduce by $a$ resulting in a new electricity bill (NEB). In addition, a set of additional benefits (like marketing or health advantages) of ecocertification would increase the rent by $c$. From that it can be seen that if the owner pays for energy the rent would be higher for certified buildings by $c$ but lower by $a(c-a)$ (columns 1 and 3). In this case the benefit to the owner is a net rent consisting of the basic rent plus the monetary value of c (if the tenant is willing to pay) while the tenant gains the business benefits of $c$. This assumes the basic rent required by the owner not to change after making a property efficient which means that the owner would not attempt to exploit the efficiency cost saving by increasing the rent by this amount (a). This can be expected to be the case in a competitive market if the cost of introducing efficiency is either ignored or amortized and included in energy bill changes $a$. If the tenant covers electricity in a certified building the rent would increase by $a$ as the total price that an occupant is willing to pay for office space remains the same as in column 1 but electricity bill is now smaller. In effect, the saving that a tenant makes on an energy bill is added to rent. Additional benefits of certification should also 
be considered, thus, in this case the rent would be higher by $(c+a)$ (columns 2 and 4). While tenants are willing to pay the same amount for the basic rent plus utility bills regardless of efficiency of the space the owner can expect to receive the same basic rent plus the efficiency cost saving (a). In addition if the tenants are also willing to pay for the additional business benefits of efficiency $(c)$ then this amount would also be added to the total rent paid. Regardless of who pays for energy bills should tenants not be willing to pay for benefits of efficiency other than the cost savings then $c$ should be zero.

A lower energy bill should translate into a lower operating expense (OpEx) as long as other charges remain equal or decrease. Generally, expenses, like general maintenance, are expected to decrease since solutions such as maximizing the use of natural lightning generate little or no additional costs (GSA, 2008). A lower OpEx should provide benefits to whoever is responsible for paying this charge.

There is some evidence that special features of a building are reflected in higher rents. For example, , Doiron (1992) shows that adding an atrium to a building increases its OpEx but also its rents. The author concludes that there is a direct rental premium associated with a building having a special feature. Given the number of intangible benefits associated with energy efficiency a similar effect is expected for benefits other than cost savings.

In effect, it appears that the total effect of energy efficiency on rents is not as straightforward as it might seem. For the purpose of this paper benefits of energy efficiency can be divided by how they are expected to be transmitted to rents:

- energy cost savings designated as (a) and transmitted through OpEx and

- other benefits described by $(c)$ and transmitted directly through certification premium independently of other variables. 


\subsection{Alternative concepts}

Not everyone agrees with the concept of benefits of efficiency resulting in a direct cost saving and a phenomenon named a 'rebound effect' is gaining currency in the mainstream economic literature. Sorrell and Dimitropoulos (2008) sum up the argument by relating the initial fall in energy prices due to lower aggregate demand to a subsequent rise of demand triggered by simple price elasticity of demand. There is historical evidence for this claim based on the introduction of efficient lightning bulbs in the first half of the twentieth century (Herring, 2006). Numerous market failures in the process of transmission of the benefits to involved parties may also pose a challenge to generating full profits of increased energy efficiency (Brown, 2001). For example, it has been suggested that a premium on energy efficiency may be an effect of temporary overpricing, due to misinformation regarding the environmental performance of assets, rather than of an efficient market pricing (Fuerst et al., 2012). In fact, some researchers state that energy efficient and/or eco-certified buildings do not generally use any less energy than their inefficient or non-certified equivalents (Scofield, 2009) or that at least a part of the green building cohort has failed to live up to expectations of lower energy consumption (Newsham et al, 2009, Wedding \& Crawford-Brown, 2007). The authors of these studies do concede, however, that the difficulty of achieving a perfect 'apple-to-apple' comparison across buildings makes it impossible to answer the question with certainty.

\section{Research question}

The purpose of this research is to find if energy cost changes associated with energy efficiency improvements are influencing office rents. The question relates to a process that consists of a chain of interactions. Theory explaining why and how those elements are connected has been presented above. Based on that reasoning three hypotheses have been constructed to examine this theory in context of the research question. 
Hypothesis 1: Energy efficient properties have lower operating expenditures compared to inefficient buildings.

This hypothesis will indicate the effect of eco-certification on rent is expected to be transmitted via operating expenses.

Hypothesis 2: The combined effects of certification vary depending on who pays energy bills.

Testing this hypothesis will show if the effect of energy cost change is indeed affecting rent. It can also validate findings of hypothesis 1 should the results be consistent.

Hypothesis 3: If the rent effect of energy cost changes is isolated from certification, remaining effects of certification are independent of who pays energy bills.

This hypothesis can show that eco-certification variable can proxy for changes in energy costs but also that this effect can be isolated based on who pays electricity bills. This can validate hypothesis 2 should the findings be consistent.

\section{Current literature}

A number of papers investigated effects of eco-certification on rents (Eichholtz et al., 2010, Fuerst and McAllister, 2011a, and others mentioned later) but none has focused exclusively on isolating the impact of energy cost changes. While these have been estimated theoretically (Norford et al., 1994) their transmission to rents has not been investigated.

There is little research available on the topic of determinants of operating expenses in office buildings mainly due to the fact that aside from energy few other cost items can be objectively measured independently of their financial value. Nevertheless, characteristics like size, number of storeys and others have been related to the amount of operating costs that a building can generate (Macsporan and Tucker, 1995). Pivo and Fisher (2010) claim that utility bills are $12.9 \%$ higher for Energy Star Certified offices but do not mention total operating 
expenses or present any evidence for that claim. Miller et al. (2010) present evidence that energy certified buildings have higher operating costs although their results are not statistically significant. The above evidence gives no support to hypothesis 1 and shows the need for investigating the relation between eco-certification and operating expenditure.

The amount of research that finds financial benefits of energy efficiency is not large but is growing fast. Researchers have found significant rent premium at levels ranging from around 3\% (Eichholtz et al., 2010, Fuerst and McAllister, 2011a) to as much as 15\% and more (Wiley et al., 2010). OpEx is rarely used as an explanatory factor in this research area and those papers that do adjust for this variable find relations to rent of a variable statistical significance (significant - Hendershott et al., 2002, insignificant - Miller et al., 2010). Most of the papers mentioned above adjust for lease terms by introducing a dummy variable for a net/gross lease which is sufficient for capturing an overall rental premium but does not enable capturing the changing sign of the alternations in rent related to changes in energy bills. In conclusion, there is some support towards hypothesis 2 as a rental premium has been found many a time and operating expenses have been shown to be a significant rent determining factor. Nevertheless, there is no previous research that adjusts for the effect of lease terms on the sign of the rental adjustment.

Research discussed above shows the aggregate effect of energy efficiency on rents and gives some support to hypothesis 3. However, little research has been done on isolating the influence of individual factors like cost savings. In those papers that have attempted this task the influence of OpEx on rent was not statistically significant (Miller et al., 2010). Other individual effects of energy efficiency have been found (e.g. occupancy rate - Fuerst, 2011b) but an influence on rent has not been separated from the aggregate rental premium. Although it has never been directly tested hypothesis 3 can be expected to hold only if the theory of transmitting the benefit of energy cost savings through operating costs is correct. 


\section{Data}

Data used in this research has been provided by CoStar Group, Inc. This database provides detailed building level data on almost 3 million buildings in the US. Due to database extraction constraints a limited sample had to be selected. In effect, properties located in four largest US office markets have been selected as a sample. This has been guided by two assumptions regarding those markets. First, that total size of a market is not correlated with building characteristics that are important for this research thus reducing selection bias. Second, that bigger markets have a higher trading volume, are likely to be more liquid and have a larger number of professional participants and in effect could be more efficient (Wang 2000) thus finding an effect of cost savings would be easier to see in rent prices (Levine et al., 1995). US real estate markets have been ranked by size according to CoStar market report for Q4 2011 and the following four were at the top of this list: New York, Washington DC, Los Angeles, Northern New Jersey.

Although limiting the research to only four markets may negatively affect appropriateness of the results to be generalized diversity of the selected areas help mitigate this issue. Figure2 presents employment industries of each market as percentage of total employment in the area. Five biggest industries of each market are presented. The figure indicates the industrial composition of selected markets and shows that breakdown of employment in most cities

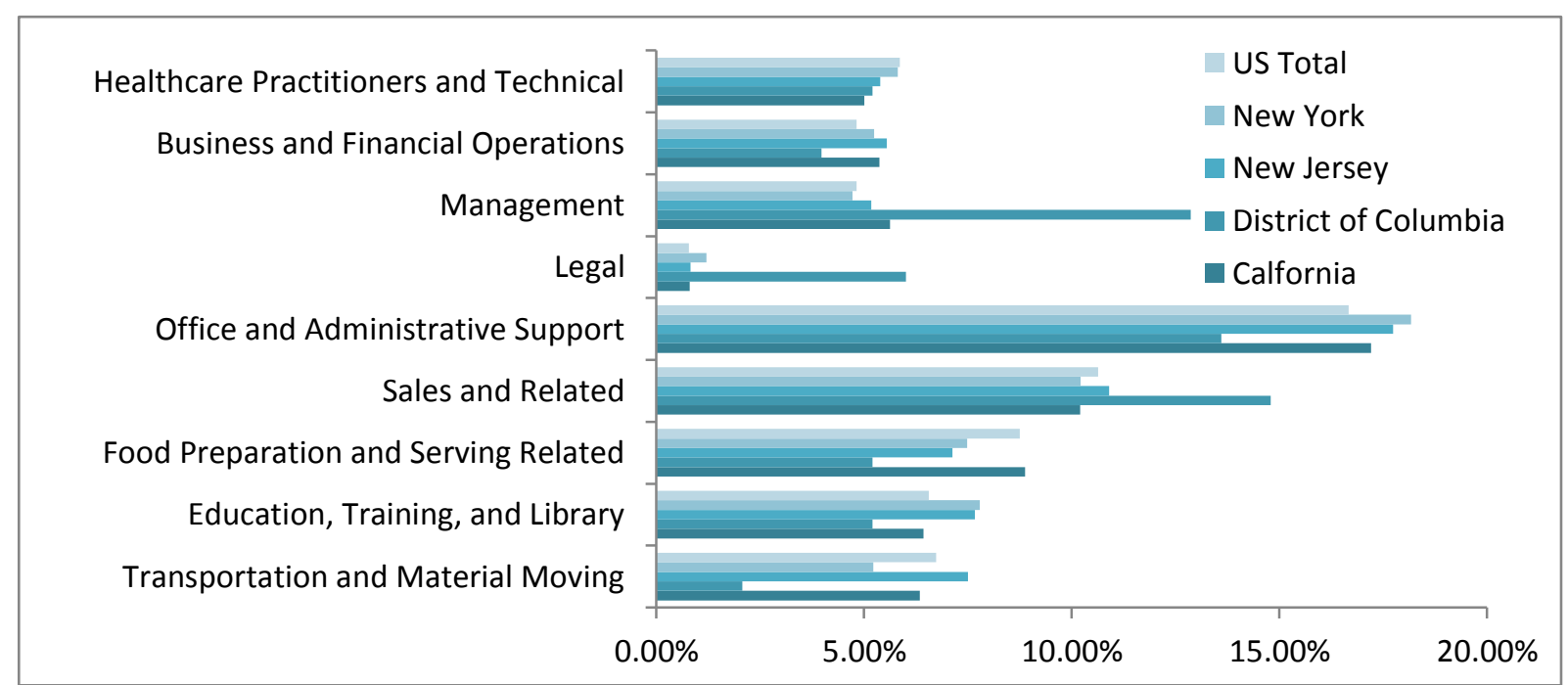

Figure2. Employment in biggest industries as percentage of total employment in the area. Source: US Department of 
resembles an overall composition of industries in United States, however, Washington DC provides diversity in the sample.

Diversity of geographical location provided variances in climate to which buildings in the sample are exposed. Diversification regarding characteristics of buildings such as age, size or number of stories also seems to be satisfactory (see Figure4.). Moreover, there seem to be considerable differences between markets indicating that key variables are not correlated with market size.

The sample was further limited to class A, B and C buildings to ensure only comparable substitutes of office space are included in the sample. Although this may be a potential source of a selection bias from the population of all offices it seems to give a representative sample of the office market and limits statistical issues with the data.

The parameters defined above yielded a sample of 41,964 properties. However, many buildings in the sample had incomplete information on some of the features that are important for this research (like operating expenses or lease type). In effect, a sample of 2,760 observations with complete information on all variables presented in Figure4 has been selected for the research. The omission of variables of interest in the remaining data was investigated to check for a selection bias but no issues were identified. 


\begin{tabular}{|c|c|c|c|c|c|c|}
\hline Variable & Description & Mean & St.Dev. & Min & Max & Count \\
\hline \multicolumn{7}{|l|}{ Location } \\
\hline NY & Dummy variable is 1 for properties based in New York & 0.21 & 0.40 & 0 & 1 & 569 \\
\hline LA & Dummy variable is 1 for properties based in Los Angeles & 0.21 & 0.41 & 0 & 1 & 588 \\
\hline DC & Dummy variable is 1 for properties based in Washington & 0.33 & 0.47 & 0 & 1 & 911 \\
\hline S1 & $\begin{array}{l}\text { Dummy is } 1 \text { for } 25 \% \text { most expensive submarkets in a } \\
\text { particular market }\end{array}$ & 0.27 & 0.44 & 0 & 1 & 733 \\
\hline S2 & $\begin{array}{l}\text { Dummy is } 1 \text { for } 25-50 \% \text { of the most expensive } \\
\text { submarkets in a market }\end{array}$ & 0.23 & 0.42 & 0 & 1 & 624 \\
\hline S3 & $\begin{array}{l}\text { Dummy is } 1 \text { for } 50-75 \% \text { of the most expensive } \\
\text { submarkets in a market }\end{array}$ & 0.26 & 0.44 & 0 & 1 & 718 \\
\hline \multicolumn{7}{|c|}{ ( } \\
\hline A1 & Dummy variable is 1 for properties built 4-3 years ago & 0.03 & 0.16 & 0 & 1 & 73 \\
\hline $\mathrm{A} 2$ & Dummy variable is 1 for properties built 5-14 years ago & 0.11 & 0.31 & 0 & 1 & 296 \\
\hline A3 & Dummy variable is 1 for properties built $29-15$ years ago & 0.25 & 0.44 & 0 & 1 & 701 \\
\hline A4 & Dummy variable is 1 for properties built $49-30$ years ago & 0.26 & 0.44 & 0 & 1 & 709 \\
\hline A5 & Dummy variable is 1 for properties built $69-50$ years ago & 0.10 & 0.29 & 0 & 1 & 264 \\
\hline A6 & Dummy variable is 1 for properties built $99-70$ years ago & 0.16 & 0.37 & 0 & 1 & 450 \\
\hline A7 & Dummy variable is 1 for properties built $>100$ years ago & 0.09 & 0.28 & 0 & 1 & 242 \\
\hline \multicolumn{7}{|c|}{ ( } \\
\hline OpEx & Annul Operating Expenditure per sq. ft. of a property* & $\$ 6.58$ & $\$ 5.41$ & $\$ 0.01$ & $\$ 48.1$ & 2760 \\
\hline OP1 & Dummy is 1 for properties certified in years 2008-2009 & 0.04 & 0.19 & 0 & 1 & 104 \\
\hline OP2 & Dummy is 1 for properties certified in years 2002-2007 & 0.05 & 0.22 & 0 & 1 & 136 \\
\hline OP3 & Dummy is 1 for properties certified in years 1998-2001 & 0.01 & 0.10 & 0 & 1 & 26 \\
\hline OP4 & Dummy is 1 for properties certified before 1995 & 0.00 & 0.06 & 0 & 1 & 10 \\
\hline \multicolumn{7}{|c|}{ Physical Characteristics } \\
\hline CLA & Dummy is 1 if property is a class A building & 0.21 & 0.41 & 0 & 1 & 577 \\
\hline CLB & Dummy is 1 if property is a class $B$ building & 0.49 & 0.50 & 0 & 1 & 1341 \\
\hline PlotS & Plot Size in acres & 3.96 & 32.25 & 0 & 560 & 2760 \\
\hline St & Number of Storeys & 6.58 & 8.10 & 1 & 77 & 2760 \\
\hline Size** & Size of the property in sq ft. & 35.49 & 30.54 & 2.92 & 170 & 2760 \\
\hline \multicolumn{7}{|l|}{ Lease } \\
\hline $\mathrm{EB}$ & Dummy is 1 if tenant pays electricity & 0.37 & 0.48 & 0 & 1 & 1029 \\
\hline \multicolumn{7}{|c|}{ Research specific } \\
\hline Cert & Dummy is 1 if the property has an energy certificate & 0.09 & 0.29 & 0 & 1 & 251 \\
\hline EB_CE & $\begin{array}{l}\text { Interaction of EB and Cert. Equals } 1 \text { if both variables are } \\
1 \text { and } 0 \text { otherwise }\end{array}$ & 0.02 & 0.14 & 0 & 1 & 52 \\
\hline Rent & Rent per sq ft. & $\$ 27.41$ & $\$ 13.71$ & $\$ 3$ & $\$ 158$ & 2760 \\
\hline EB_LnOPEX & $\begin{array}{l}\text { Interaction of } E B \text { and } \operatorname{Ln}(\mathrm{OpEx}) \text {. Product of } \\
\text { multiplication. }\end{array}$ & 3.95 & 3.07 & 0 & 48.1 & 977 \\
\hline
\end{tabular}

Figure 4. Description of variables and summary statistics.

* OpEx is recorded as an overall cost for buildings regardless of who is responsible for covering particular items of that bill.

** Descriptive statistics for Size have been shown in tens of thousands.

All dummy variables take values of 1 or 0 
Operating Expenses consist of all

costs of occupancy including both

fixed costs that do generally do not

vary (ex. insurance) and variable

costs (ex. utilities, maintenance) that

change depending on occupancy

and market conditions. Tax is not

included. Most importantly for this

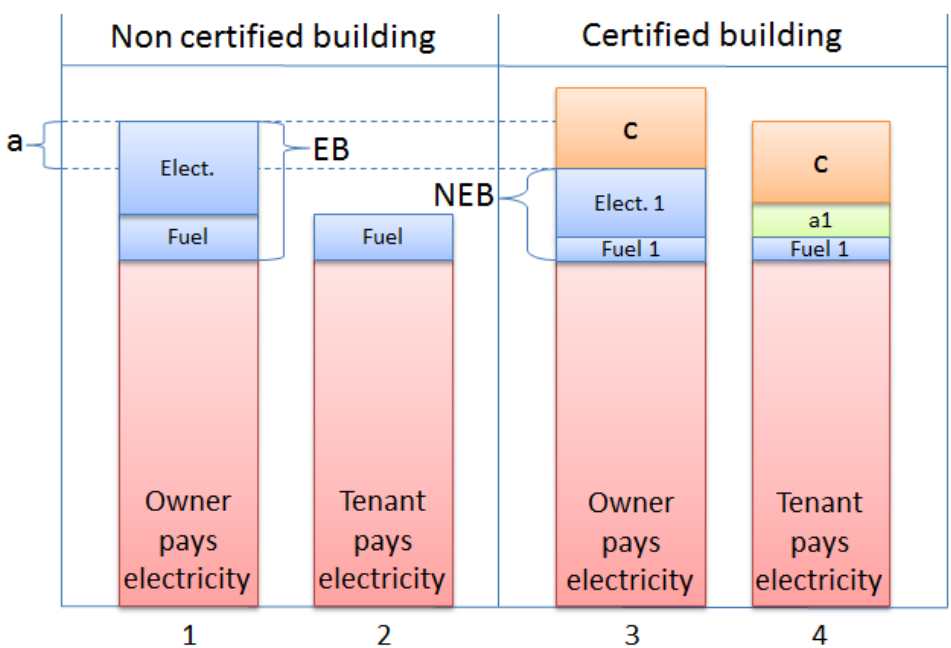

Figure 5. Rent paid to owner and lease terms when responsibility for energy bills is approximated by a responsibility for electricity bills.

research OpEx variable includes

energy costs.

In the sample over thirty types of leases determining who pays particular operating expenses in a building were identified. For the purpose of this research these have been divided into two groups of leases: ones that oblige the tenant to pay at least the electricity bill and ones that leave this obligation with the landlord (energy charge is included in the rent). While the cost of electricity does not always account for the total cost of energy used in a building it often is the biggest item on that bill (Perez-Lombard et al., 2008). In result, in this paper the responsibility to cover the total cost of energy usage is approximated by an obligation to pay for electricity. In result an approximation of the responsibility to cover the total cost of energy usage by an obligation to pay for electricity seems justifiable.

Figure1 illustrated how responsibility for paying energy bills is expected to affect rents in certified buildings. Should this be limited to paying for electricity the effect would be different (see Figure5). Assuming that the total energy bill can consist of electricity bill and a bill for any other fuel that a building is using (coal, oil, gas etc.) the effect of the assumption that paying for electricity is identical with paying for total energy can be investigated. The difference to Figure1 is that instead of a premium for total energy efficiency $(a=a 1+a 2)$ there 
now is a smaller premium for electricity efficiency $(a 1=a-a 2)$. It can now be seen that when approximating responsibility for an energy bills with responsibility for an electricity bill an assumption is made that $a 2$ is negligibly small compared to $a$. This is true as long as a reduction in electric energy accounts for majority of a reduction in total energy bills. Given that electricity expenditure per square foot has been reported to be on average more than three times more than cost of any other fuel (EIA, 2011) it can be concluded that for the purpose of this research being responsible for a total energy bill can be reasonably approximated with being responsible for an electricity bill.

Two types of eco-certification are included in the CoStar database: LEED and EnergyStar. Despite differences in awarding certificates both protocols include requirements on energy efficiency.

A further addition to the data has been made to control for an effect of submarket location. Using historical data from the CoStar database a ranking of submarkets with historically highest rents has been created based on average rents over 10 quarters prior to the recording period of the remaining data (Q2 2012). Based on the results the sample was divided into 4 subsamples reflecting the position of particular submarkets in their respective markets.

At this point it is important to state that this research may be influenced by a self-selection bias of agents that have a high inherit demand for energy services being more likely to self-select into energy efficient properties. While the considerable homogeneity of energy based services required by office space use limits possible differences in the use of energy

\begin{tabular}{|l|c|c|c|c|}
\hline \multirow{2}{*}{} & \multicolumn{2}{|c|}{ Certified } & \multicolumn{2}{c|}{ Non Certified } \\
\cline { 2 - 5 } & Rent & OpEx & Rent & OpEx \\
\hline Mean & 39.55 & 10.83 & 26.19 & 6.15 \\
\hline St. Dev. & 12.77 & 4.26 & 13.21 & 5.33 \\
\hline Min & 16.00 & 0.54 & 3.00 & 0.01 \\
\hline Max & 85.32 & 27.81 & 157.5 & 48.05 \\
\hline Count & \multicolumn{2}{|c|}{251} & \multicolumn{2}{c|}{2509} \\
\hline
\end{tabular}

Figure 6. Descriptive statistics divided by certification. Differences in both means are statistically significant at $1 \%$ confidence interval 
between various agents and makes this bias unlikely it could potentially result in operating expenses being artificially inflated.

\section{Methodology}

It can be seen from Figure6 that certified buildings have statistically significantly higher rents and operating expenses. However, as a number of other building features may influence this relation this analysis does not show causality. In order to control for the large number of factors that influence prices in real estate hedonic modelling will be used.

All three hypotheses require an estimation of a price controlled for building characteristics. This can be done using the following model (Ekeland et al., 2002):

$$
\text { Price }_{i}=\alpha+\beta x_{i}+\varepsilon_{i}
$$

Where $x_{i}$ is a vector of explanatory characteristics of a building, $\beta$ is a vector of respective parameters that are to be estimated and $\varepsilon_{i}$ is a normally distributed random error with a mean of zero. Regression constant is given by $\alpha$ and coefficients assigned to each of the explanatory variables can be interpreted as the contribution of the respective characteristic to the total price.

\subsection{Analysis}

The first hypothesis requires an estimation of OpEx prices controlled for building characteristics. This can be done using the following model:

$$
\begin{gathered}
\text { (1) } \ln \left(O p E x_{i}\right)=\alpha+\beta_{1} N Y_{i}+\beta_{2} L A_{i}+\beta_{3} D C_{i}+\sum_{n=1}^{7} \beta_{4} A_{n i}+\sum_{n=1}^{3} \beta_{5} S_{n i}+\sum_{n=1}^{4} O P_{n i}+ \\
\beta_{7} C L A_{i}+\beta_{8} C L B_{i}+\beta_{9} \ln \left(\text { Rent }_{i}\right)+\beta_{10} \ln \left(\text { Plot }_{i}\right)+\beta_{11} \ln \left(\operatorname{St}_{i}\right)+\beta_{12} \ln \left(\text { Size }_{i}\right)+ \\
\beta_{13} E B_{i}+\beta_{14} \operatorname{Cert}_{i}+\varepsilon_{i}
\end{gathered}
$$

This model has been guided by McSporran and Tucker's (2010) paper on this topic. Location variables are a proxy for differences in building management standards, energy use practices, 
weather conditions, local regulations and cost of maintenance services. Age variables are proxy for the type of construction technology and materials used as well as design type of a building. Although building size is not expected to be a considerable driver of per square foot OpEx other physical characteristics of a building control for important determinants of operating costs like differences in required heating, general maintenance and use of lifts. Finally, additional dummy variables, specific to this research, on lease type and certification were added. $E B$ variable controls for a contracted obligation to pay energy bills and is expected to have a negative coefficient if the tenant is responsible for it to proxy for a better incentive to control the use of energy. Certification variable determines the impact of ecocertification on operating expenses. Should hypothesis 1 be true this effect is expected to be significant and negative.

Hypotheses two and three both require estimation of a rent model although they include different variables. The rent model used in this paper has been based on Fuerst and McAllister's (2011) work and adjusted to suit a slightly different sample. The following model will be used:

$$
\begin{gathered}
\text { (2) } \quad \ln \left(\text { Rent }_{i}\right)=\alpha+\beta_{1} N Y_{i}+\beta_{2} L A_{i}+\beta_{3} D C_{i}+\sum_{n=1}^{7} \beta_{4} A_{n i}+\sum_{n=1}^{3} \beta_{5} S_{n} i+\beta_{6} C L A_{i}+ \\
\beta_{7} C L B_{i}+\beta_{8} \ln \left(\text { Plot }_{i}\right)+\beta_{9} \ln \left(\text { St }_{i}\right)+\beta_{10} \ln \left(\text { Size }_{i}\right)+\beta_{10} E B_{i}+\beta_{11} \text { Cert }_{i}+\beta_{12} \text { EB_Cert }_{i}+\varepsilon_{i}
\end{gathered}
$$

Use of similar models is very popular in real estate literature and effects of all included variables are well understood. Lease variable is specific for this research and is expected to have a negative coefficient to reduce the rent if a tenant pays for electricity. Certification variable has also been added and is expected to have a positive sign to proxy for total benefits of eco-certification to tenants. While this base model is useful for validation of the parameters against literature it has been altered in order to test individual hypotheses. 


\begin{tabular}{|c|c|c|c|}
\hline \multirow{2}{*}{ 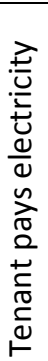 } & Yes & $\begin{array}{l}\text { Reduced by } \\
\text { electricity bill } \\
\text { (-EB) }\end{array}$ & $\begin{array}{l}\text { Reduced by electricity bill (-EB), Increased } \\
\text { by energy efficiency discount }(+a) \text {, } \\
\text { increased by other certification benefits }(+c) \\
(-\mathbf{E B}+\mathbf{a}+\mathbf{c})\end{array}$ \\
\hline & No & Benchmark & $\begin{array}{l}\text { Reduced by energy efficiency discount }(-a) \text {, } \\
\text { increased by other certification benefits }(+c) \\
\text { (c-a) }\end{array}$ \\
\hline & & No & Yes \\
\hline & & & Building is certified \\
\hline
\end{tabular}

Figure7. Combined effects of EB, EB_CE and Cert on rent where 'EB' - electricity bill, 'a' - energy efficiency discount on that bill and ' $c$ ' - other certification benefits.

Hypothesis 2 is tested by adding $E B \_C E$ as an explanatory variable to the base model in order to explore the interaction between who pays the electricity bill and certification of a property. Should the hypothesis be true the sum of coefficients is expected to have a variable magnitude (Figure7). A tenant should be willing to pay a lower rent if they need to cover electricity ($E B)$ but that discount should be smaller for energy efficient properties $(-E B+a)$. The combined effect in a certified property should would also include other benefits of certification $(-E B+a+c)$. Should the landlord pay for electricity the rent should be reduced by energy efficiency discount $(-a)$ but increased by other benefits $(+c)$. Since it is only possible to observe the combined effect of energy efficiency and other certification benefits through the coefficient of Cert variable we can find the energy efficiency coefficient in the following way:

If $x$ and $z$ are defined by equations:

$$
z=-E B+a+c, \quad x=-a+c
$$

Then $a$ can be calculated by:

$$
a=\frac{(z-x+E B)}{2}
$$


Since $a, z$ and $x$ can be estimated from regression 2 in the following way:

$$
z=\beta_{10}+\beta_{11}+\beta_{12} \quad x=\beta_{11} \quad-E B=\beta_{10}
$$

$a$ can be represented as:

$$
\text { (3) } \quad a=\frac{\beta_{12}}{2}
$$

$\beta_{12}$ is a coefficient of $E B \_C E$ and statistical significance of $a$ is identical to the one of $\beta_{12}$.

$E B$ indicates responsibility for the energy bill, thus its coefficient represents the total amount of that charge. Energy efficiency saving should naturally be lower than the total energy cost. In effect the reduction in energy cost due to energy efficiency denoted as $a$ is expected to be positive and smaller than the coefficient of $E B$.

Hypothesis 3 is examined by adding operating expense controls $\left(\ln (O p E x), \ln (O p E x) \_E B\right.$, $O P 1, O P 2, O P 3, O P 4)$ to the model used in hypothesis 2 and comparing results of the tests. Including these controls should isolate the energy cost changes from the total certification benefit. In fact, it will be possible to test if energy cost saving is the only benefit of energy efficiency that depends on lease contract terms. Should that be true the remaining effects should be independent of who pays energy bills. Coefficients of OpEx variables are expected to be consistent with findings from hypothesis 1 testing.

Should the PE_CE coefficient be zero it can be assumed that certification is no longer related to who pays energy bills. Therefore, since energy costs are the only component of certification premium that depends on $E B$ it would follow that this component has been isolated from certification premium and associated with effects of the OpEx controls. 
Figure 8. Heteroskedasticity Adjusted (White 1980) Regression Results

\begin{tabular}{|c|c|c|c|c|c|c|c|c|c|}
\hline \multirow{3}{*}{ Dep. Var. } & \multicolumn{3}{|c|}{ Table 1.} & \multicolumn{3}{|c|}{ Table 2.} & \multicolumn{3}{|c|}{ Table 3.} \\
\hline & \multicolumn{3}{|c|}{$\operatorname{Ln}(O p E x)$} & \multicolumn{3}{|c|}{ Ln(Rent) } & \multicolumn{3}{|c|}{$\operatorname{Ln}($ Rent) } \\
\hline & Coefficient & Std. EI & rror & Coefficient & Std. E & Error & Coefficient & Std. & Error \\
\hline Constant & -0.869 & 0.378 & $* *$ & 2.597 & 0.097 & $* * *$ & 2.545 & 0.097 & $* * *$ \\
\hline \multicolumn{10}{|l|}{ Location } \\
\hline NY & 0.625 & 0.092 & $* * *$ & 0.624 & 0.035 & $* * *$ & 0.550 & 0.035 & $* * *$ \\
\hline LA & 0.133 & 0.062 & $* *$ & 0.203 & 0.019 & $* * *$ & 0.184 & 0.020 & $* * *$ \\
\hline $\mathrm{DC}$ & 0.002 & 0.060 & & 0.161 & 0.017 & $* * *$ & 0.147 & 0.018 & $* * *$ \\
\hline \multicolumn{10}{|l|}{ Age } \\
\hline $\mathrm{A} 1$ & -0.524 & 0.234 & $* *$ & -0.102 & 0.047 & $* *$ & -0.077 & 0.047 & \\
\hline $\mathrm{A} 2$ & -0.255 & 0.197 & & -0.143 & 0.039 & $* * *$ & -0.126 & 0.039 & $* * *$ \\
\hline A3 & -0.183 & 0.192 & & -0.227 & 0.038 & $* * *$ & -0.212 & 0.038 & $* * *$ \\
\hline A4 & -0.106 & 0.193 & & -0.200 & 0.039 & $* * *$ & -0.191 & 0.039 & $* * *$ \\
\hline A5 & -0.227 & 0.197 & & -0.253 & 0.044 & $* * *$ & -0.233 & 0.044 & $* * *$ \\
\hline A6 & -0.025 & 0.198 & & -0.233 & 0.045 & $* * *$ & -0.227 & 0.044 & $* * *$ \\
\hline A7 & -0.055 & 0.203 & & -0.204 & 0.048 & $* * *$ & -0.199 & 0.048 & $* * *$ \\
\hline \multicolumn{10}{|l|}{ Submarket } \\
\hline S1 & 0.123 & 0.055 & $* *$ & 0.413 & 0.019 & $* * *$ & 0.388 & 0.019 & $* * *$ \\
\hline S2 & -0.082 & 0.054 & & 0.173 & 0.017 & $* * *$ & 0.171 & 0.017 & $* * *$ \\
\hline S3 & -0.119 & 0.050 & $* *$ & 0.074 & 0.017 & $* * *$ & 0.077 & 0.016 & $* * *$ \\
\hline \multicolumn{10}{|l|}{ OpEx } \\
\hline OP1 & 0.058 & 0.087 & & N/A & & & -0.045 & 0.030 & \\
\hline OP2 & 0.502 & 0.063 & $* * *$ & N/A & & & -0.006 & 0.021 & \\
\hline OP3 & -0.310 & 0.171 & $*$ & N/A & & & -0.068 & 0.048 & \\
\hline OP4 & 0.102 & 0.170 & & N/A & & & 0.010 & 0.089 & \\
\hline $\operatorname{Ln}(O p E x)$ & N/A & & & N/A & & & 0.077 & 0.009 & $* * *$ \\
\hline EB_LNOPEX & N/A & & & N/A & & & -0.035 & 0.011 & $* * *$ \\
\hline \multicolumn{10}{|l|}{ Characteristics } \\
\hline CLA & 0.239 & 0.075 & $* * *$ & 0.232 & 0.024 & $* * *$ & 0.206 & 0.024 & $* * *$ \\
\hline CLB & 0.075 & 0.046 & & 0.096 & 0.016 & $* * *$ & 0.085 & 0.016 & $* * *$ \\
\hline Ln(Rent) & 0.581 & 0.060 & $* * *$ & N/A & & & N/A & & \\
\hline Ln(PlotS) & 0.135 & 0.025 & $* * *$ & -0.017 & 0.006 & $* * *$ & -0.025 & 0.006 & $* * *$ \\
\hline $\operatorname{Ln}(S t)$ & 0.275 & 0.048 & $* * *$ & 0.074 & 0.015 & $* * *$ & 0.053 & 0.015 & $* * *$ \\
\hline $\operatorname{Ln}($ Size $)$ & 0.001 & 0.034 & & 0.024 & 0.010 & $* *$ & 0.023 & 0.010 & $* * *$ \\
\hline $\mathrm{EB}$ & -0.120 & 0.045 & $* * *$ & -0.131 & 0.015 & $* * *$ & -0.080 & 0.019 & $* * *$ \\
\hline Cert & 0.112 & 0.045 & $* *$ & 0.078 & 0.017 & $* * *$ & 0.068 & 0.017 & $* * *$ \\
\hline EB_Cert & N/A & & & -0.069 & 0.040 & $*$ & -0.045 & 0.040 & \\
\hline Model Stat. & $R^{2}: 0.44$ & F-stat: $\varepsilon$ & 86.59 & $R^{2}: 0.647$ & F-stat: & 239.5 & $R^{2}: 0.662$ & F-stat: & 198.1 \\
\hline
\end{tabular}

$* * *, * *$ and $*$ denominate $1 \%, 5 \%$ and $10 \%$ significance levels respectively 


\section{Results}

\subsection{Hypothesis 1}

Table1 (Figure8.) shows heteroskedasticity adjusted (White, 1980) results of a hedonic model relating annual operating expenses per square foot to appropriate variables discussed in the section above. The overall fit of the model may seem quite low with only $44 \%$ of changes explained by independent variables but as related literature points out operating performance of a building is mainly determined by the quality and motivation of its management (McSporran and Tucker, 2010). As this aspect is difficult to quantify and doing so is not the primary focus of this work this factor was not included in this model. In effect, the $R^{2}$ of $44 \%$ seems satisfactory for the purpose of identifying effects of eco-certification on OpEx.

Location of a building seems to have a big influence on OpEx with buildings in New York being by far most expensive to run and those in Washington not displaying a significant difference to ones in New Jersey. Recently built properties have the lowest OpEx, however, the effect of age of a building may have an insignificant impact on that cost unless the building is between 3 and 4 years old. Location in a particular submarket has a more consistent effect with operating costs decreasing for the middle $50 \%$ of the ranked submarkets and increasing for the top quarter with the bottom $25 \%$ as a benchmark. Compared to expenses recorded within the last three years OpEx fluctuated with time giving an average increase of 50.2\% in years 2002-2007, and decrease of 31\% between 1998 and 2001. Effect of class of a building is considerable with a premium for class A (23.9\%) being more than three times the premium of class B (7.5\%) against the baseline of class C. Although, statistically significant effects of rent and plot size seem very small with $1 \%$ change in either variable causing respectively $0.581 \%$ and $0.135 \%$ change in OpEx. As expected, while buildings with more storeys seem to be more expensive to run, due to additional infrastructure maintenance, 
the effect of building size on OpEx may not be significant. As predicted, if the tenant is responsible for the electricity bill operating expenses are lower.

Finally, the effect of certification is statistically significant at $5 \%$ confidence interval; however, the sign of the coefficient is opposite to expectations. From Table1 it would seem that for an energy certified property operating expenses are on average higher by $11.2 \%$ than for non-certified buildings. This is an increase of around \$0.69 in OpEx per square foot (based on average OpEx for the non-certified sample). Compared to $\$ 0.39$ (4\%) increase found by Miller et al. (2010) this seems reasonable, although, contrary to their research, here the result is significant. The data from Table1 seems not to support hypothesis 1 and the conclusion from the test is that eco-certification does not directly correlate to lower operating expenditure.

Lack of evidence for hypothesis 1 indicates that lower energy costs may not be a direct result of energy efficiency improvements. However, the test looked at total operating expenses rather than energy cost leaving room for additional factors which could have influenced the result. Testing hypothesis 2 can help provide more information on how that process works.

\subsection{Hypothesis 2}

Table2 (Figure8.) shows heteroskedasticity adjusted (White, 1980) regression results of a test described in the previous section. The basic model has good explanatory power similar to the work presented by Fuerst and McAllister (2011c) as well as other similar research on the subject (Eichholtz et al., 2010). Most statistical data in the table is as expected as are all the usual real estate phenomena (e.g. the nonlinear effect of age). Both

\begin{tabular}{|c|c|c|}
\hline $\begin{array}{c}\text { Tenant pays } \\
\text { electricity }\end{array}$ & \multicolumn{2}{|c|}{ Total effect on rent } \\
\hline Yes & $-13.1 \%$ & $-12.2 \%$ \\
\hline No & benchmark & $+7.8 \%$ \\
\hline $\begin{array}{c}\text { Building is } \\
\text { certified }\end{array}$ & No & Yes \\
\hline
\end{tabular}

Figure 9. Estimates of individual and combined $\%$ effects of EB and Cert on rents. market and submarket locations are significant with New York again being the most 
expensive. Age discount is increasing initially but reduces as buildings are becoming classics. Furthermore class and number of storeys have, as expected, a significant positive influence on rents. Signs of coefficients of plot size and building size are surprising and different to the results presented by Fuerst and McAllister but they match results of other similar pieces of research (Eichholtz et al., 2010) which would suggest that the effect is different for different samples.

An average discount of $13.1 \%$ for paying electricity in non-certified buildings translates into \$3.43 (based on average rent for the non-certified sample) and can be represented as $55.8 \%$ of an average OpEx (based on average OpEx for the same sample). Although this seems high against expectations of an energy bill to be around 30\% of total OpEx both the positive sign of the adjustment and the fact that its magnitude is lower than an average total OpEx are consistent with expectations. However, the combined results for responsibility for electricity bill and eco-certification are not as predicted. While it seems clear that a responsibility for electricity expenses is important for rents, certification of a building does not appear to always influence it (Figure9). Energy efficient buildings seem to generate higher rents if an owner is paying for electricity but there seems to be little change if that is not the case.

If the effect of energy cost savings is separated from other coefficients using equation (3) the resulting $a$ is equal to -0.0343 . This indicates an overall negative effect of energy efficiency on rents of $3.43 \%$ independent of lease terms and a positive effect of other certification benefits $(c)$ of $4.41 \%$. This is consistent with the findings of the previous hypothesis indicating that since certification is related to increased operating expenses the financial consequence should be negative. Although a raise in energy costs is not an expected result it has been considered by literature as one of possible outcomes (Herring, 2006) and supported by some evidence (Lin and Young, 2009; Scofield, 2009 a and b). In effect, a conclusion that energy costs increase with certification seems plausible. Since energy cost change could be 
defined as a change in energy bill minus a periodical amortization of costs of introducing efficiency (section 2.3) one of possible explanations for a negative value of that effect would be that the costs outweigh the benefits. However, there is strong evidence of profitability of energy efficiency's ability to decrease the total amount of energy units used given a constant demand for output (section 2.1). In result, an increase in energy bills relative to expectations driven by increased output, described theoretically in section 2.4, seems a likely explanation of a negative effect of energy efficiency improvements.

Findings of the test are consistent with the hypothesis that the effect of energy cost changes (in this case an increase) is dependent on terms of lease contracts. In effect, hypothesis 2 can be confirmed.

It could be argued that a factor unrelated to energy costs but related to certification and lease terms is influencing the above results. The below test for hypothesis 3 will test for presence of such factor.

\subsection{Hypothesis 3}

Table3 (Figure8.p.19) presents heteroskedasticity adjusted (White, 1980) results of a regression based on a rent model including additional variables controlling for operating. As expected, the explanatory power of the model increases as OpEx is an important determinant of rents. Other explanatory variables are consistent with the results from Table2.

Influence of operating expenses is significant but also, as expected, closely related to who pays energy bills. Of measurement years only measurements taken between 2008 and 2009 are statistically influencing rents and the year of recording does not seem to be a generally significant determinant of rents. 
As expected, the interaction of certification and $E B$ variables is no longer statistically significant after OpEx controls have been included. A conclusion can be drawn that association of certification with responsibility to pay for energy bills has been isolated and transferred to OpEx variable. In result, it would seem that energy costs have been isolated from certification variable and associated with operating expenses. This gives support to hypothesis 3.

\subsection{Discussion of results}

In the previous section all results were interpreted individually and validated against expectations. However, in order to answer the research question all results need to be brought together in an attempt to form a coherent conclusion.

Hypothesis 1 seems not to find support in empirical evidence. In fact, the opposite seems to be true: that certification increases operating expenses. As counterintuitive as this seems it is not entirely unexpected (see the background chapter). As mentioned in the introductory chapter, explanations suggested in the literature include an energy rebound effect, increased maintenance costs, self-selection effect and increase in the overall use of utilities. From the test for hypothesis 1 it is impossible to establish which of those, if any, is the real reason. Moreover, it is not possible to see if certification is causing an increase energy use or an increase in other costs. While it is not clear what effect causes the increase in OpEx there is a correlation between eco-certification and increased operating expenses. The results indicate that the hypothesis that eco-certification lowers operating costs should be rejected. However, although indicative, the evidence is not strong enough to support a claim that certification leads to higher OpEx. For the purpose of this paper the fact that certification is associated with higher OpEx is sufficient basis to look into the transmission mechanism of that change to rent. 
Hypothesis 2 assumes that rent effects of any changes in energy costs associated with certification would be dependent on who pays energy bills. An empirical analysis finds evidence of interaction between who pays energy bills and certification. Since energy costs are the only effect of certification that is expected to interact with lease terms this is indicative evidence of energy cost changes being included in the certification premium. Using equation (3) it was possible to isolate the change on energy bills which has been found to be an increase. This is entirely consistent with findings of hypothesis 1 . Should higher energy costs be associated with certification an increase in energy bills for certified properties is expected to be found. The result can be interpreted as an absolute increase in energy bills if costs of introducing efficiency are ignored or a reduction in energy bills of less than expected (relative increase) if they are accounted for.

It is possible that the relationship in hypothesis 1 has been influenced by effects other than costs of energy. This would not be affecting the results in hypothesis 2 tests as $E B$ variable control ensures that only energy bill related effects are reflected. The matrix of effects that certification and $E B$ variables have on rent (Figure9) is consistent with expectations from the methodology chapter (given the reverse effect of energy costs and results of hypothesis 1 tests). In fact, an average increase in OpEx from non-certified buildings can be estimated at \$0.69 psf (Table1 and Figure6) while the increase in rents associated with increased costs of energy can be estimated at $\$ 0.89$ psf (Table2 and Figure6). A similar magnitude of those changes is consistent with the assumption of a common driver, like a change in energy costs, although a slight difference suggests that an additional factor may influence the relation. While hypothesis 2 is confirmed an analysis of its test results gave indications of an unexpected increase of energy bills in certified properties. However, given the methodology used, this finding is only valid if changes in energy bills are the only component of certification premium that is dependent on who pays energy bills. 
Hypothesis 3 was established to investigate this assumption. By controlling rents for OpEx the energy change component of certification premium should be isolated as operating expenses are a far better proxy for that variable. In effect, certification should not have a link to who pays energy bills. Empirical test have found evidence that this indeed is the case. After controlling for OpEx EB variable was no longer interacting with certification. The conclusion of that test is that energy bill changes are indeed the only component of the total certification premium that has previously been associated with who pays energy bills. In result, conclusions from hypothesis 2 are validated.

As stated in the research question this piece of research seeks to find if changes in energy costs associated with eco-certification are reflected in rents. First, the above research has shown that certification is associated with higher operating expenditure but no direct link to energy bill could be made. Second, a relationship of eco-certification with who pays energy bills has been discovered. A relative or absolute increase in energy bills for certified properties has also been shown depending on how costs of introducing efficiency are accounted for. This indicated not only that certified properties have higher than expected energy bills but also that this effect is affecting rents. In this context it would seem that the increase in operating expenditure from hypothesis 1 can be indeed caused by an energy bill being higher than expected after introducing energy efficiency. However, the above findings would not be valid if another factor associated with who pays energy bills was affecting ecocertification premium. The last test of this research showed that this was not the case and validated findings of all previous investigations.

\section{Conclusion}

This paper reports empirical evidence of changes in cost of energy associated with energy efficiency affecting rents in US office buildings. 
A sample of four biggest US office markets has been selected and limited to 2760 properties for which required information were available from the CoStar Group database. Energy efficiency of a building has been approximated with having certification from LEED or EnergyStar and responsibility of a tenant or owner for paying energy bills with a responsibility to pay for electricity.

The results clearly indicate that changes of energy cost associated with energy efficiency certification have an influence on rents. The change is first reflected in operating expenses of building and through this charge affects rents. Although generally the sign of the effect on rent depends on which agent is responsible for energy bills its magnitude remains constant and has been calculated.

Despite the counterintuitive negative effects of eco-certification both on energy bills and on total operating expenses the certification effect on rental rates has been confirmed to be positive. This suggests that the main benefits of eco-certification may not be related to reduced energy use but to other characteristics of eco-certified buildings. However, a strong caveat is in order given the indirect nature of our energy expenditure data and more reliable metrics of energy consumption, such as detailed meter readings, are necessary to confirm these preliminary findings in future studies. 


\section{References}

Brown, M.A. (2001). Market failures and barriers as a basis for clean energy policies. Energy Policy, 29(14), pp.1197-1207.

ConSol (2008). Achieving 30\% and 50\% over ASHRAE 90.1-2004 in a Low-Rise Office Building. Study prepared for NAIOP.

DeCanio, S.J. and Watkins, W.E. (1998). Investment in energy efficiency: Do the characteristics of firms matter? Rev. Econom. Statist., 80, pp.95-107.

Doiron, J. C., Shilling, J. D. and Sirmans. C. F. (1992). Do Market Rents Reflect the Value of Special Building Features? Journal of Real Estate Research, 7(2), pp.147-156.

EIA - US Energy Information Administration (2011). Commercial Buildings Consumption by Energy Source, Selected Years, 1979-2003. Available at:

http://www.eia.gov/totalenergy/data/annual/showtext.cfm?t=ptb0209 accessed on 27/06/12

Eichholtz, P., Kok, N. and Quigley, J. M. (2010). Doing Well by Doing Good? Green Office Buildings. American Economic Review, 100(5), pp.2492-2509.

Ekeland, I., Heckman, J.J. and Nesheim, L. (2002). Identifying Hedonic Models. The American Economic Review, 92(2), pp.304-309.

Fowler, K.M. and Rauch, E.M. (2008). Assessing Green Building Performance: A Post Occupancy Evaluation of 12 GSA Buildings. Pacific Northwest National Laboratory, Richland, Washington.

Fuerst, F. and McAllister, P. (2011a). The Impact of Energy Performance Certificates on the Rental and Capital Values of Commercial Property Assets: Some Preliminary Evidence from the UK. Energy Policy, 39, pp.6608-6614.

Fuerst, F. and McAllister, P. (2011b). Eco-Labeling, Rents, Sales Prices and Occupancy Rates: Do LEED and Energy Star Labeled Offices Obtain Multiple Premiums? Ecological Economics, 70(6), pp.1220-1230.

Fuerst, F. and McAllister, P. (2011c). Green Noise or Green Value? Measuring the Effects of Environmental Certification on Office Values. Real Estate Economics, 39(1), pp.1-25.

Harvey, L.D.D. (2006). A Handbook on Low-Energy Buildings and District-Energy Systems. Fundamentals. Techniques and Examples. Earthscan Publications, London (2006), Ch. 4 and 13.

Harvey, L.D.D. (2009). Reducing energy use in the buildings sector: measures, costs, and examples. Energy Efficiency, 2, pp.139-163.

Hendershott, P.H., MacGregor, B.D. and White, M. (2002). Explaining Real Commercial Rents Using an Error Correction Model with Panel Data. Journal of Real Estate Finance and Economics, 24(1-2), pp.59-87. 
Herring, H. (2006). Energy efficiency: A critical review. Energy, 31, pp.10-20.

Kats, G. (2003). The Costs and Financial Benefits of Green Buildings-A Report to California's Sustainable Building task Force. Capital E, October.

Koomey, J.G., Webber, C.A., Atkinson, C.S. and Nicholls, A. (2001). Addressing EnergyRelated Challenges for the U.S. Buildings Sector: Results from the Clean Energy Futures Study. Energy Policy (also LBNL-47356), 29(14), pp.1209-1222.

Levine, M.D., Koomey, J.G., McMahon, J.E., Sanstad, A. and Hirst, E. (1995). Energy Efficiency Policy and Market Failures. Annual Review of Energy and the Environment, 20, pp.535-555.

Lin, J. and Young, D. (2009). Energy Efficiency in Canadian Commercial Buildings: Evidence from 2000 and 2005. id: CBEEDAC 2009-RP-03 available at: http://www.cbeedac.com/publications/documents/CommercialEnergyEfficiency_002.pdf accessed on $03 / 07 / 12$

Liu, M. and Claridge, D. E. (1999). The Maximum Potential Energy Savings from Optimizing Cold and Hot Deck Reset Schedules for Dual Duct VAV Systems. ASME Journal of Solar Energy Engineering, 121, pp.171-175.

MacSporran, C. and Tucker, S.N. (1996). Target budget levels for building operating costs. Construction Management and Economics, 14(2), pp.103-19.

Miller, N., Pogue, D., Saville, J. and Tu, C. (2010).The Operation and Management of Green Buildings in the United States. Journal of Sustainable Real Estate, 2, pp.51-66.

Newsham, G. R., Mancini, S., \& Birt, B. J. (2009). Do LEED-certified buildings save energy? Yes, but.... Energy and Buildings, 41(8), 897-905.

Norford, L.K., Socolow, R.H., Hsieh, E.S. and Spadaro, G.V. (1994). Two-to-one discrepancy between measured and predicted performance in a 'low energy' office building: insights from a reconciliation based on the DOE-2 model. Energy and Buildings, 21, pp.121-131.

Oikonomou, V., Becchis, F., Steg, L. and Russolillo, D. (2009). Energy saving and energy efficiency concepts for policymaking. Energy Policy, 37, pp.4787-4796.

Perez-Lombard, L., Ortiz, J. and Pout, C. (2008). A review on buildings energy consumption information. Energy and Buildings, 40(3), pp.394-398.

Pivo, G. and Fischer, J.D. (2010). Income, Value and Returns in Socially Responsible Office Properties. Journal of Real Estate Research, 32(3), pp.243-70.

Reichardt, A., Fuerst, F., Rottke, N. and Zietz, J. (2012). Sustainable Building Certification and the Rent Premium: A Panel Data Approach. Journal of Real Estate Research. 34(1), pp.99-126.

Scofield, J.H. (2009a). Do LEED-certified Buildings Save Energy? Not Really... Energy and Buildings, 41(12), pp.1386-90. 
Scofield, J. H. (2009b). A Re-examination of the NBI LEED Building Energy Consumption Study. Presented at the 2009 Energy Program Evaluation Conference, Portland.

Sorrell, S. and Dimitropoulos, J. (2008), The rebound effect: Microeconomic definitions, limitations and extensions. Ecological Economics, 65, pp.636-649.

Wedding, C. and D. Crawford-Brown, (2007): An Analysis of Variation in the EnergyRelated Environmental Impacts of LEED Certified Buildings, Journal of Green Building, 2, 151-170, 2007.

Wang P. (2000) Market Ef囚ciency and Rationality in Property. Investment Journal of Real Estate Finance and Economics, 21:2, 185 $\pm 201,2000$

White, H. (1980). A Heteroskedasticity-Consistent Covariance Matrix Estimator and a Direct Test for Heteroskedasticity. Econometrica, 48(4), pp.817-38.

Wiley, J.A., Benefield, J.D. and Johnson, K.H. (2010). Green Design and the Market for Commercial Office Design. Journal of Real Estate Finance and Economics, 41(2), pp.22843.

Withers, C.R. Jr. and Cummings, J.B. (1998). Ventilation, Humidity, and Energy Impacts of Uncontrolled Airflow in a Light Commercial Building. ASHRAE Transactions, 104, pp.733741.

\section{Appendix: Data selection and selection bias.}

As data in the CoStar database is normally recorded and disclosed at the discretion of the reporting party there is a risk of a reporting bias in the data especially considering the sensitive nature of some information. Limiting the sample of 41,964 properties to observation that included the information required by the model (excluding OpEx) resulted in a sample of 7,561 buildings. No material correlation of the missing data has been found to other variables. In fact only 9,465 properties reported their rents of which further observations had to be discarded due to a lack of data on important building characteristics. While this could potentially be a source of a self-selection bias caused by selective reporting it is unlikely that owners of properties would intentionally and systematically withhold information on the size of their buildings or the number of stories or elevators (which is available publically anyway). This is not the case for operating expenses. This piece of information is not only an indication of overall operating performance, important in comparing assets, but also an indication of the 
quality of how a building is maintained. In effect values that are considered by the owners to be above average or simply not favourable may not to be reported. This could potentially introduce a bias into the research and systematically lower the average reported value of operating expenses. In order to check for that bias values of OpEx in the sample can be compared to similar data from other sources.

Figure C. shows that the average OpEx in the sample is $\$ 6.58 /$ sf with a standard deviation of 5.41. Surprisingly this is much lower than an average of just over $\$ 10$ reported by Miller et al. (2010) although rigorous statistical comparison is not possible as they do not report a standard deviation. The variation may arise from a difference in geographical locations. This piece of research looks at four markets while Miller at al. looked a buildings from as many as ten. Figure C. shows how much variance there is between individual locations in the sample of this research. Using NCREIF data for the period from 1999 to 2008 Pivo and Fisher (2009) reported a relatively high average expenses of $\$ 11.58$. However, their variable included all costs rather than just operating so included items such as tax. Given an average value of tax of $\$ 6.87 /$ sf in the sample used in this paper their findings can be easily reconciled with the OpEx from Figure C. Jaffee, Stanton and Wallace (2011) report an average of \$7.7 over 5,092 observations in a dataset combing information from Trepp LLC and CoStar transaction service which is also very close to the number from Figure C. Furthermore, data from a report by BOMA (2009) is presented in the table and, where it can be directly compared, does not seem to show a significant difference from the reports of this research.

Operating expenses by location can also be broken down by class and is expected to show significant differences. Form Figure C. it would seem that this is indeed the case. From a database of Whitestone Research data on class A office buildings for individual locations has 
been extracted. The results presented in Figure C. are consistent with the findings of this paper and show no indication of a significant variance. Although no alternative external data from the researched locations could be accessed a report from the Chicago market (Dermisi 2008) gives a basis for comparison of differences between individual classes. Class A offices in Chicago paid $\$ 9.73$ which is very close to the $\$ 9.87$ found in this report. Other classes of buildings gave larger differences of Chicago's $\$ 9.14$ and $\$ 8.62$ against $\$ 7.35$ and $\$ 5.00$ in the sample for classes B and C respectively. Although they may seem different those variations fall well within the standard error of the averages reported in this paper.

As a result of the above analysis it can be concluded that the OpEx data extracted from the CoStar database shows no indication of significant unexplainable differences to data reported from other sources. While access to external sources of relevant information has been limited all comparable data that has been obtained can be reconciled with the results included in this research.

\begin{tabular}{lcccc} 
& \multicolumn{4}{c}{ This research } \\
\cline { 2 - 5 } & A & B & C & ALL \\
\hline NY & 17.37 & 13.29 & 9.90 & 12.46 \\
& $(5.42)$ & $(5.66)$ & $(5.17)$ & $(6.01)$ \\
& 89 & 233 & 247 & 569 \\
\hline DC & 9.02 & 5.25 & 3.55 & 6.20 \\
& $(3.43)$ & $(4.21)$ & $(3.50)$ & $(4.36)$ \\
& 286 & 498 & 127 & 911 \\
\hline LA & 9.83 & 5.15 & 3.10 & 5.12 \\
& $(3.57)$ & $(3.67)$ & $(3.75)$ & $(4.31)$ \\
& 93 & 274 & 221 & 588 \\
\hline NNJ & 6.00 & 3.36 & 2.54 & 3.48 \\
& $(2.65)$ & $(2.25)$ & $(2.03)$ & $(2.52)$ \\
& 109 & 336 & 247 & 692 \\
\hline ALL & 9.87 & 7.35 & 5.00 & 6.58 \\
& $(5.06)$ & $(5.74)$ & $(4.96)$ & $(5.41)$ \\
& 577 & 1341 & 842 & 2760
\end{tabular}

\begin{tabular}{cc}
$\begin{array}{c}\text { BOMA (2009) average } \\
\text { including all classes }\end{array}$ & $\begin{array}{c}\text { Whitestone } \\
\text { Research class A } \\
(2013)\end{array}$ \\
\hline 13.1 & 17.88 \\
& \\
\hline 8.41 & 9.27 \\
& \\
\hline [8.69] & 8.72 \\
Los Angeles only & \\
\hline [9.62] & 6.93 \\
whole New Jersey & \\
\hline 8.11 & \\
All US
\end{tabular}

Figure C. Operating expenses in dollars per square foot. For data from this paper a mean value is given first (in normal font) followed by a standard error (in brackets) and a number of observations (in italics). For combined Los Angeles and Orange county and for Northern New Jersey only no BOMA data was available thus related but not directly comparable values are shown. 